\title{
Biometano produzido a partir de biogás de ETEs e seu uso como combustivel veicular
} Biomethane produced from WWTP biogas and used as vehicle fuel

\section{INTRODUÇÃO}

Em estações de tratamento de esgoto (ETEs) no Brasil, o biogás pode ser gerado a partir do tratamento anaeróbio do esgoto, utilizando, dentre outras tecnologias, o reator anaeróbio ascendente de manta de lodo (UASB) e a partir do tratamento de lodos em digestores anaeróbios.

O biogás é uma fonte flexível de energia renovável e seu uso pressupõe a transformação da energia química nele presente. Pode ser usado para produzir energia térmica (combustão), energia elétrica e térmica (cogeração ou CHP), combustível veicular ou ser injetado na rede de gás natural e assim servir a qualquer um dos usos citados, desde que atenda às exigências de qualidade de gás para cada uso pretendido.

Com relação aos usos citados, deve-se diferenciar a utilização de biogás e de biometano. 0 biogás pode ser utilizado para a produção de energia elétrica e energia térmica (aquecer, secar, resfriar), após remoção das principais impurezas, como umidade, siloxanos e $\mathrm{H}_{2} \mathrm{~S}$, presentes neste. $\mathrm{O}$ biometano é resultante do enriquecimento ou beneficiamento do biogás, que consiste na remoção de dióxido de carbono $\left(\mathrm{CO}_{2}\right)$ e de outros componentes traço ainda presentes no biogás e aumento do seu poder calorífico. Pode ser utilizado como substituto do gás natural veicular (GNV), após compressão e posterior armazenamento, desde que atendidas as exigências de qualidade do órgão regulador competente (adaptado de PROBIOGÁs, 2015).

Na maioria das ETEs não há um uso sistemático do biogás, sendo queimado em "flare". Existem algumas experiências de uso para geração de energia e/ou calor e de produção de biometano para uso como combustível veicular. Nesse sentido, já houve na Companhia de Saneamento Básico do Estado de São Paulo (Sabesp), em meados da década de 1980, uma tentativa de utilização do biometano em substituição ao GNV em veículos nas ETEs Pinheiros e Leopoldina. Atualmente está em andamento um projeto para produção de biometano a partir do biogás gerado nos digestores anaeróbios de lodo da ETE Franca, localizada na cidade de Franca (SP), e seu uso como combustível veicular em frota própria, a princípio.

O biometano é considerado um gás renovável que pode se tornar um recurso despachável com a aplicação de técnicas de armazenamento e ser utilizado a qualquer tempo ou lugar, onde for necessário seu uso, seja como gás para geração de energia, calor ou combustível veicular. 
Dentre os combustíveis fósseis, o gás natural tem o maior potencial de redução dos gases de efeito estufa. 0 metano ou gás natural comprimido tem um potencial de redução das emissões da ordem de $21 \%$ e $24 \%$ em comparação com diesel e petróleo, respectivamente. Quando se mistura $20 \%$ de biometano ao gás natural, essa redução das emissões passa para 39\%, em comparação aos derivados de petróleo, podendo chegar a reduções da ordem de $97 \%$ de emissões com biometano puro. Assim, com $20 \%$ de biometano as emissões são da ordem de $24 \mathrm{gCO}_{2} \mathrm{eq} / \mathrm{km}$, e com $100 \%$ de biometano as emissões são da ordem de $5 \mathrm{gCO}_{2}$ eq $/ \mathrm{km}$ (adaptado de DENA, 2010 e DENA, 2017).

Atualmente, as tecnologias para produção e compressão do biometano consomem em torno de $20 \%$ da energia contida no biogás. No processo de produção de biometano, em torno de $80 \%$ da energia contida no biogás é transformada em energia limpa e as perdas de calor deste processo são minimizadas (CUCCHIELLA et al., 2017). Nos sistemas de cogeração (CHP), em torno de 35$40 \%$ da energia do biogás é convertida em eletricidade e a outra parcela de energia é obtida na forma de calor, e, a menos que seja aproveitada, é dissipada ou perdida. Os sistemas de cogeração conseguem suprir em torno de $40 \%$ da energia contida no biogás como energia para rede, 0 que representa em torno da metade da energia do biometano, que pode ser injetada na rede de gás natural ou utilizada como combustível veicular. Assim sendo, o uso de biogás na forma de biometano pode ser uma alternativa competitiva ao uso de biogás em sistemas de cogeração de calor e energia, apresentando como vantagem o fato de poder ser armazenado, transportado e usado de forma flexível como energia. É considerada uma energia sustentável despachável, que pode complementar outras formas de energia sustentável, mais sujeitas a flutuações, como a eólica e a solar (BUDZIANOWSKIA, 2017).

\section{TECNOLOGIAS DE BENEFICIAMENTO DE BIOGÁS - PRODUÇÃO DE BIOMETANO}

Independentemente do uso do biogás, recomenda-se que seja tratado para a remoção de impurezas como umidade, $\mathrm{CO}_{2}, \mathrm{H}_{2} \mathrm{~S}$ e siloxanos, de modo a evitar problemas de corrosão e incrustação nos equipamentos (URBAN et al., 2009). Assim, os autores sugerem as seguintes etapas para a remoção de compostos do biogás: remoção de elevadas concentrações de sulfeto de hidrogênio $\left(\mathrm{H}_{2} \mathrm{~S}\right)$ dentro do próprio digestor ou em sistema próprio para este fim; remoção de concentrações traço de $\mathrm{H}_{2} \mathrm{~S}$; remoção de dióxido de carbono $\left(\mathrm{CO}_{2}\right)$ e outros componentes do biogás; remoção da umidade, que deve ser realizada antes da etapa de remoção do $\mathrm{CO}_{2}$, quando a tecnologia de remoção utilizar um processo a seco.

As tecnologias de remoção de $\mathrm{CO}_{2}$ comumente usadas estão baseadas nos princípios de absorção (transferência para fluidos), de adsorção (transferência para superfícies sólidas), de separação por membranas e criogênica. Com relação às tecnologias de absorção, podem ser utilizados solventes líquidos como água, glicóis e aminas e ser chamadas, respectivamente, lavador com água e pressão, lavador físico com solventes orgânicos e lavador químico com aminas.

Segundo levantamento das plantas de biometano na Europa (WILKEN et. al, 2016), 41\% das unidades existentes utilizam a tecnologia de lavagem com água e pressão; $25 \%$ a lavagem química com aminas; $18 \%$ a de adsorção por oscilação de pressão (em inglês Pressure Swing Adsorption - PSA); $8 \%$ a separação por membranas; $7 \%$, a lavagem física com solventes e algumas poucas plantas com a tecnologia de separação por criogenia. Todas essas tecnologias, exceto a criogenia, são consideradas estado da técnica (BEIL, 2017).

A escolha da tecnologia mais adequada para remoção de $\mathrm{CO}_{2}$ está na dependência no grau 
de tratamento requerido, do tamanho da planta, concentração de contaminantes presentes no biogás e valor do biogás após remoção de impurezas ou após beneficiamento, na qualidade de biometano (POLO et al., 2017). Ainda com relação à escolha da tecnologia de remoção de $\mathrm{CO}_{2}$, Beil (2017) considera que primeiro é necessário elaborar um projeto, conhecer outras plantas, estabelecer critérios para avaliação e escolha, solicitar propostas e avaliá-las e por último decidir.

Em geral, todas as tecnologias têm desempenho similar, mas diferem em detalhes como demanda de energia elétrica e parâmetros de processo como alta concentração no biometano e baixa perda de metano para atmosfera. No entanto, o melhor critério de escolha sempre deve tomar por referência as condições locais do empreendimento.

\section{CONSIDERAÇÕES SOBRE PRODUÇÃO DE BIOGÁS E BIOMETANO}

Em 2015, o número de plantas de biogás na Europa era de 17.376, o que equivale a uma produção de energia de 138.340 GWh (EBA, 2016). Desse total, 16.834 plantas de biogás (ou 88\%) estavam concentradas em oito países (Alemanha, Reino Unido, Suécia, Suíça, Holanda, França, Áustria e Itália), que equivale a $119.306 \mathrm{GWH}$ de energia ou $81 \%$ do total produzido na Europa. Com relação aos usos do biogás na Europa, os países estudados são responsáveis por $88 \%$ da geração de energia elétrica a partir de biogás, $91 \%$ do calor usado e $99 \%$ do biometano produzido. Este percentual corresponde à produção de 421 de plantas biometano, assim distribuídas: Alemanha, com 185 plantas, seguida por Reino Unido, com 80, Suécia, com 61, Suíça, com 35, Holanda, com 21, França, com 20, Áustria, com 13, e Itália com 6. Nestes países, com relação ao uso do biogás, em média, $12 \%$ é para biometano e $88 \%$ para geração de energia elétrica e calor. Ainda de acordo o mesmo estudo, Alemanha, Suécia e Reino Unido são os países que lideram, tanto no número de instalações de biometano como em infraestrutura de uso deste. Há, no entanto, diferenças significativas com relação à intensidade do uso de biometano nos vários países. Na Suécia, $74 \%$ de todo biogás é dedicado à produção de biometano, enquanto na Holanda, na Suíça e na Alemanha são 26\%, 19\% e 15\%, respectivamente; na Áustria e no Reino Unido são 9\%, e na França apenas 2\%. No Reino Unido, Alemanha, Áustria e França, por exemplo, quase todas as plantas de biometano estão conectadas à rede de gás natural devido às políticas e programas de incentivos presentes nesses países (adaptado de VAN GRINSVEN, 2017).

Com base em dados de 2016, o uso do biometano no setor de transporte está mais concentrado na Europa, com destaque para Alemanha, Suécia, Suíça e Reino Unido, mas também Estados Unidos. A estimativa em nível internacional era de 500 plantas produzindo biometano com qualidade similar à do gás natural. Os custos de produção de biometano dependem parcialmente da fonte de biogás usada e principalmente do tamanho/capacidade da unidade de beneficiamento. Além disso, muitos países possuem políticas de isenção de taxas para uso veicular do biometano, subsídios para investimentos ou incentivos para injeção de biometano na rede de gás natural. O Brasil tem alto potencial de produção e uma extensa frota de veículos movidos a GNV e infraestrutura de postos de distribuição de GNV (IRENA, 2017).

Com relação à produção de biometano para uso no Brasil, destacam-se as seguintes inciativas para uso veicular e possibilidade de injeção na rede:

- Projeto de produção de biometano em uma Cooperativa dos Citricultores Ecológicos do Vale do Caí (Ecocitrus), em Montenegro, no Rio Grande do Sul. 
- Projetos apoiados pela Itaipu Binacional, Parque Tecnológico Itaipu (PTI) e Centro Internacional de Energias Renováveis-Biogás (CIBiogás), no Paraná, com destaque para produção de biometano a partir de mistura de esgoto, restos orgânicos e poda de grama e seu uso em frota própria.

- Experiência do Aterro Dois Arcos, em São Pedro da Aldeia no Rio de Janeiro, com produção de biometano para uso veicular.

- Projeto de beneficiamento de biogás para produção de biometano para uso veicular, na ETE Franca, pertencente à Sabesp e detalhado a seguir.

Este projeto é resultado de um Acordo de Cooperação Técnica Internacional, firmado entre a Sabesp e o Instituto Fraunhofer da Alemanha (Fraunhofer IGB), financiado pela iniciativa internacional de proteção ao clima (IKI) do Ministério Alemão do Meio Ambiente (BMUB) por meio de créditos de carbono pelo lado alemão e com contrapartida da Sabesp, pelo lado brasileiro. No acordo, assinado em 2015, está prevista a implantação de uma planta de beneficiamento de biogás, reservatório de biogás e posto de combustível e de todas as obras de infraestrutura para implantação desses equipamentos, bem como a interligação do projeto com as instalações de biogás existentes na ETE e todas as adequações necessárias para atendimento das exigências dos órgãos reguladores competentes e estabelecidas as responsabilidades de cada uma das partes para viabilização do projeto.

Os equipamentos foram doados pelo Instituto Fraunhofer e a infraestrutura e demais custos ficaram sob a responsabilidade da Sabesp. Foram desenvolvidos em conjunto os projetos, os trâmites para a nacionalização dos equipamentos doados e o atendimento às exigências dos órgãos anuentes, e iniciado o comissionamento dos equipamentos, parte em junho de 2017, com previsão de conclusão até final de 2017 e partida do siste- ma de produção de biometano para uso em veículos em início de 2018.

O valor do projeto na época era da ordem de R\$ 7.377.639,46 (EUR 2.126.120,75 - cotação de agosto/2015), sendo $R \$ 4.116 .690,00$ (EUR 1.185.000,00) provenientes de recurso externo do BMUB por meio do Fraunhofer, com a doação de equipamentos do sistema de beneficiamento para Sabesp e a prestação de assistência técnica especializada para acompanhamento de todas as etapas do projeto de pesquisa, e R\$ 3.260.949,46 (EUR 939.754,75), recurso da Sabesp, com a realização das obras das bases civis e da linha de biogás, instalação de sistema elétrico, adaptação de veículos para biometano, pagamento de taxas, impostos e licenças de órgãos reguladores (EBERT MIKI, 2017).

O principal objetivo deste projeto é alcançar um efeito positivo para o meio ambiente, especialmente uma redução de emissões de gases de efeito estufa, pela substituição de combustíveis fósseis e uso do biogás em vez de queimá-lo em "flare". Outros aspectos relevantes são: demonstrar a viabilidade do uso de biometano como combustível veicular, gerado com biogás de ETEs, considerando as condições locais, que incluem ambiente regulatório e possibilidades de comercialização para terceiros.

\section{ASPECTOS REGULATÓRIOS DO BIOMETANO DE ETES}

A Agência de Proteção Ambiental dos Estados Unidos (EPA) recentemente classificou o biometano como um biocombustível avançado, reconhecendo-o como renovável e de baixo carbono, representando uma potencial oportunidade para a redução da emissão de Gases do Efeito Estufa (GEE), classificando o biometano como "Gás natural renovável" (adaptado de EPA, 2016).

No Brasil, a regulação quanto ao controle de qualidade e especificação do biometano é de competência do ente Federal, no caso, a Agência Na- 
cional do Petróleo, Gás e Biocombustíveis (ANP), que desde 2011 é responsável pela regulação, autorização e fiscalização das atividades do setor produtivo de biocombustíveis. Nos últimos anos houve avanços significativos, em termos de regulamentação, com o estabelecimento das regras de aprovação do controle da qualidade e da especificação do biometano destinado ao uso veicular e às instalações residenciais, industriais, oriundo de produtos e resíduos orgânicos agrossilvopastoris e comerciais, por meio da Resolução ANP n 8/2015 e de aterros sanitários e de ETEs, por meio da Resolução ANP n 685/2017. Esta última somente foi aprovada após a definição de metodologia de coleta e de análises para determinação de compostos orgânicos voláteis e siloxanos, que são compostos que podem estar presentes em biogás e biometano oriundos de aterros sanitários e ETEs e que precisam ser monitorados. Essas metodologias foram publicadas em janeiro de 2017, como as normas ABNT: NBR 16562, NBR 16560 e NBR 16561.

Quanto à exploração dos serviços locais de gás canalizado no território brasileiro, esta é uma atribuição do estado, que pode fazê-lo diretamente ou mediante concessão. Alguns estados, como São Paulo, Rio de Janeiro, Santa Catarina, Paraná e Rio Grande do Sul, apresentam avanços no estabelecimento de regras para uso e comercialização de biometano. Dentre essas regras, incluem-se: definição de políticas para promover a produção e o consumo do biometano, condições de injeção de biometano na rede e definição dos percentuais mínimos em relação ao gás natural, fixação de preço de referência e das formas de comercialização do biometano. No Estado de São Paulo, essa atribuição é da Agência Reguladora de Saneamento e Energia do Estado de São Paulo (Arsesp), que estabeleceu por meio da Deliberação ARSESP Nº 744/2017 as condições e critérios para que o biometano fornecido pelos produtores possa ser inserido na rede pública de gás, canalizado e distribuído. A definição dos preços a serem praticados para biometano e o volume compulsório a ser adquirido serão regulamentados pelo Governo de São Paulo, por meio do Comitê Gestor do Programa Paulista de Biogás, conforme previsto no Decreto Estadual $58.659 / 12$, que trabalha na elaboração de diretrizes para incentivar a ampliação da participação de energias renováveis na matriz energética do Estado de São Paulo e o potencial do estado na geração de biometano.

\section{PROJETO E INSTALAÇÃO DO SISTEMA DE BENEFICIAMENTO DE BIOGÁS NA ETE FRANCA}

O projeto de beneficiamento de biogás está implantado na ETE Franca, que possui uma vazão de tratamento de esgotos de $450 \mathrm{~L} / \mathrm{s}$ e produz em torno de $2.600 \mathrm{Nm}^{3} /$ dia de biogás nos seus digestores anaeróbios de lodo (sendo 60\% - 65 $\%$ de metano).

A escolha do local de implantação do projeto tomou por referência o layout da ETE e as distâncias seguras recomendadas para instalação do sistema de beneficiamento.

O projeto consta de uma planta de beneficiamento de biogás, acondicionada em contêiner construído, um reservatório de biogás à pressão atmosférica (28 mbar), um posto de biometano e de toda infraestrutura civil, elétrica e de segurança para instalação do sistema de beneficiamento (contêiner), além da construção de uma nova linha de biogás. No croqui da Figura 1, observa-se que a unidade de beneficiamento está interligada aos biodigestores através do reservatório de biogás. Os "flares" já existentes na ETE serão utilizados para queimar o gás excedente, quando o reservatório de biogás estiver cheio ou quando o sistema de beneficiamento por qualquer motivo seja tirado de operação (adaptado de EBERT MIKI, 2017). 


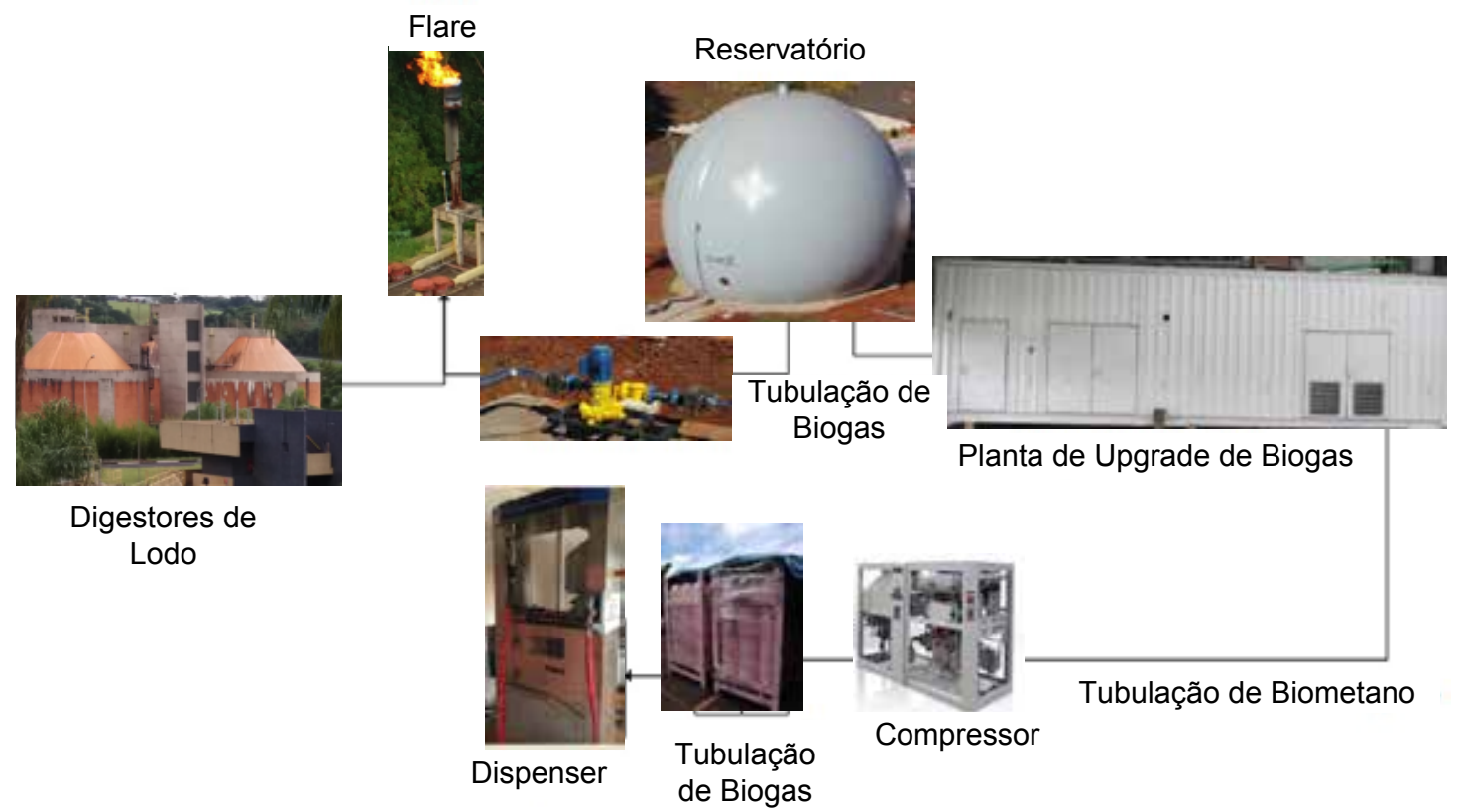

Figura 1: Sistema de Beneficiamento de Biogás Fonte: Adaptado de WAELKENS E STERNAD, 2011.

O sistema de beneficiamento de biogás proposto considera o tratamento de $120 \mathrm{Nm}^{3} / \mathrm{h}$ e as características médias do biogás com: $65 \%$ de $\mathrm{CH}_{4}, 30 \%$ de $\mathrm{CO}_{2}, 4 \%$ de $\mathrm{H}_{2} \mathrm{O}, 0,8 \%$ de $\mathrm{N}_{2}$ e $0,2 \%$ de $\mathrm{O}_{2}$ para produzir biometano com teor de $\mathrm{CH}_{4}$ em tornode $97 \%$.

A maior parte das unidades de tratamento está dentro do contêiner. Na figura 2 é apresentado o flu- xograma com as unidades de pré-tratamento para compressão, condicionamento e desumidificação do biogás, remoção de $\mathrm{H}_{2} \mathrm{~S}$ do biogás e pré-filtros de carvão ativado para remoção de siloxanos e outros micropoluentes presentes no biogás. Tais etapas de tratamento são necessárias antes da unidade de remoção de $\mathrm{CO}_{2}$, que utiliza a tecnologia de PSA.

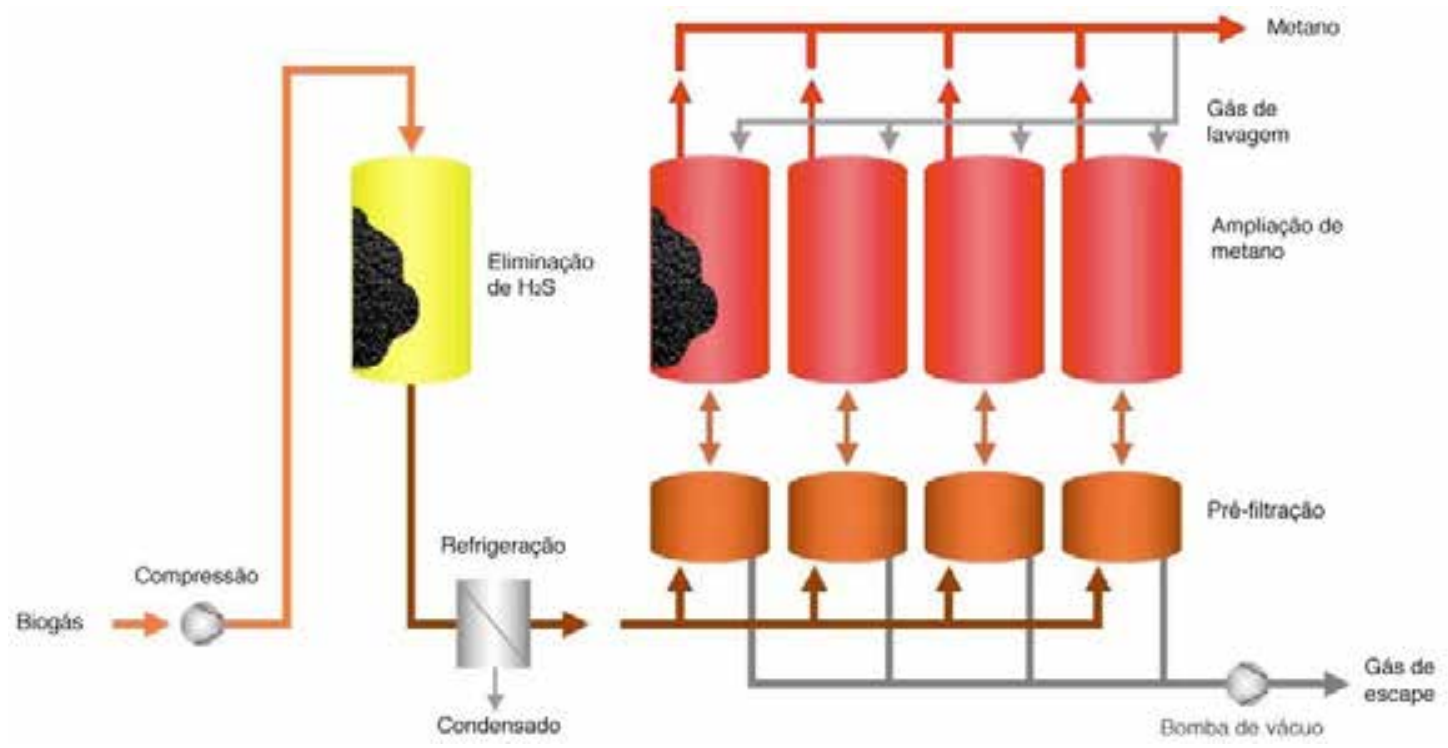

Figura 2 - Sistema de beneficiamento de biogás, instalado dentro do contêiner (adaptada de SCHULTE-SCHULZE BERNDT, 2006). 
Dentro do contêiner, o componente principal é o sistema de enriquecimento de metano, que emprega a tecnologia que trabalha dentro do princípio da adsorção por oscilação de pressão (PSA), caracterizada pela adsorção preferencial do $\mathrm{CO}_{2}$ em relação ao $\mathrm{CH}_{4}$, em meio adsorvente, quando submetido à pressão.

Neste projeto, a unidade de PSA é composta de quatro colunas de adsorção preenchidas com peneiras moleculares de carbono (PMC) e arranjadas em série para garantir a produção contínua de metano e em condições normais de operação. Cada coluna passa por um ciclo alternante de adsorção-regeneração, conforme descrito a seguir (adaptado de WAELKENS E STERNAD, 2011), sendo que o $\mathrm{CO}_{2}$ é adsorvido neste material e o metano sai pelo topo da coluna de adsorção.

A adsorção do $\mathrm{CO}_{2}$ ocorre em alta pressão, e durante esta fase o biogás flui através da coluna de adsorção, sendo o CO2 adsorvido na superfície interna da PMC, enquanto o metano sai pela parte superior da coluna para ser encaminhado ao posto de combustível. Antes que a PMC esteja saturada, a fase de adsorção é interrompida e a próxima coluna inicia a adsorção, enquanto a regeneração passa a ocorrer na coluna na qual anteriormente ocorria a adsorção.

A desorção (inversão da adsorção) e regeneração da PMC ocorre por meio de uma redução gradativa da pressão dentro da coluna de adsorção até alcançar o vácuo, fazendo com que as moléculas anteriormente adsorvidas sejam dessorvidas para a fase gasosa. Apenas durante a redução da pressão para o vácuo o gás succionado é enviado para a atmosfera, uma vez que as concentrações de metano neste caso estão abaixo de 5\%. Após a fase de vácuo na coluna de adsorção, a PMC está completamente regenerada e pode adsorver $\mathrm{CO}_{2}$ novamente.

Do sistema de beneficiamento, o biometano segue para o posto de combustível, instalado sobre em base civil construída para esse fim. Este posto de combustível é constituído por: compressor com capacidade máxima de processamento de $180 \mathrm{Nm}^{3} / \mathrm{h}$ de biometano de uma pressão de 4 bar para 250 bar, reservatório de alta pressão, composto por 32 cilindros de 125 l, divididos em 4 subskids, com volume total de 4.000 litros, interligados entre si e que trabalham com uma pressão de 250 bar e dispenser para abastecimento dos veículos adaptados da frota de Franca, com duas linhas de abastecimento simultâneas e pressão de trabalho de até 220 bar.

Quando em operação, o sistema de beneficiamento de biogás poderá produzir até $1.700 \mathrm{Nm}^{3} /$ dia de biometano, que equivalente a um potencial de substituição de 1.700 litros de gasolina comum por dia.

\section{RESULTADOS-IMPLANTAÇÃO DA INFRAESTRUTURA, MONTAGEM E COMISSIONAMENTO}

Os projetos, obras de infraestrutura para instalação dos equipamentos doados e providências técnicas foram desenvolvidos em conjunto pelas equipes da Sabesp (RG - área operacional/TX-área de pesquisa) e do Instituto Fraunhofer.

A seguir fotos do recebimento e descarregamento do contêiner na ETE de Franca e das obras de infraestrutura, como bases civis para instalação do contêiner, do posto de combustível e do reservatório. 


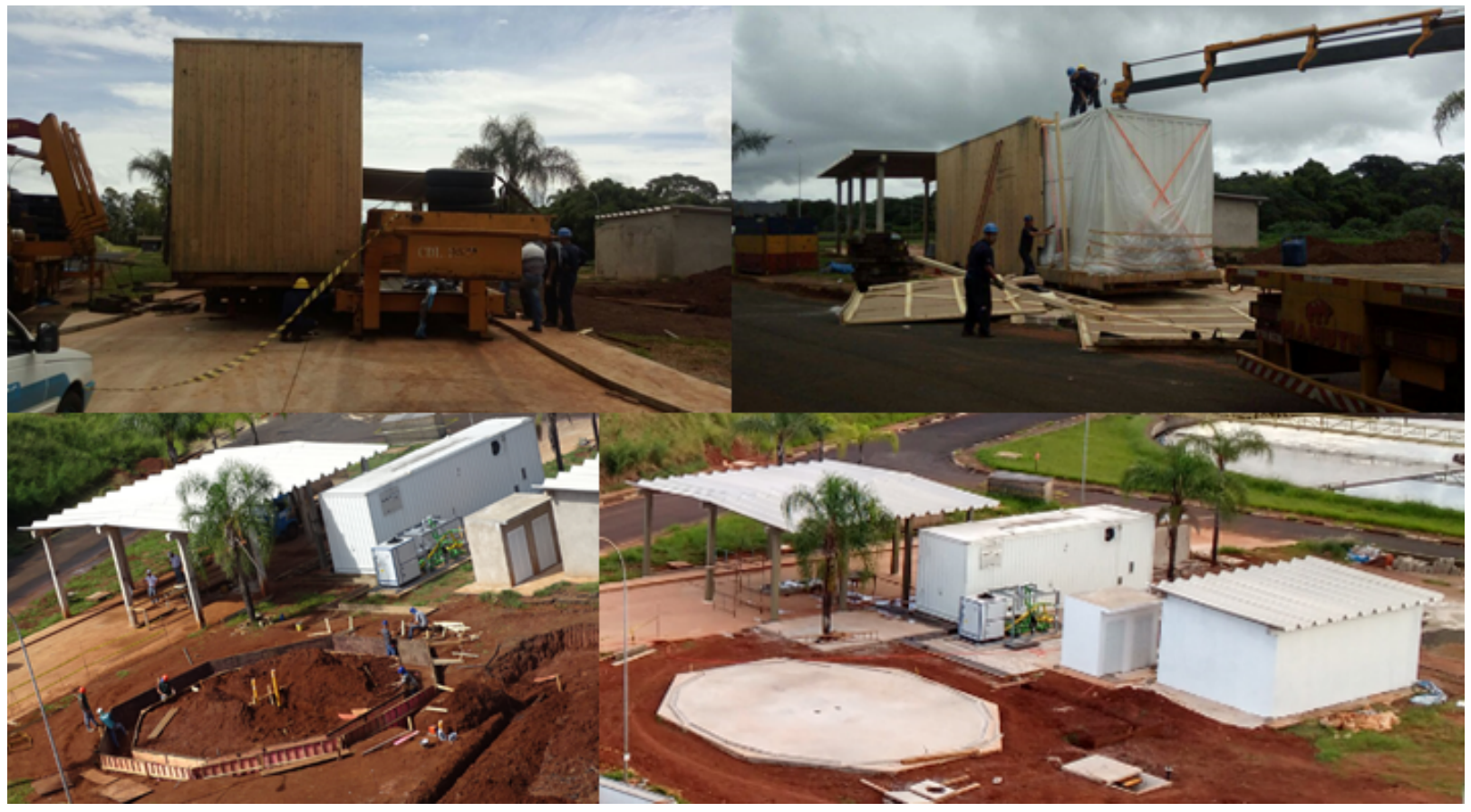

Figura 3. Vista da chegada do contêiner e seu descarregamento na ETE e da infraestrutura civil para instalação do contêiner, posto de combustível e do reservatório (fase de construção e base concluída). Fonte: Sabesp- RG, 2017
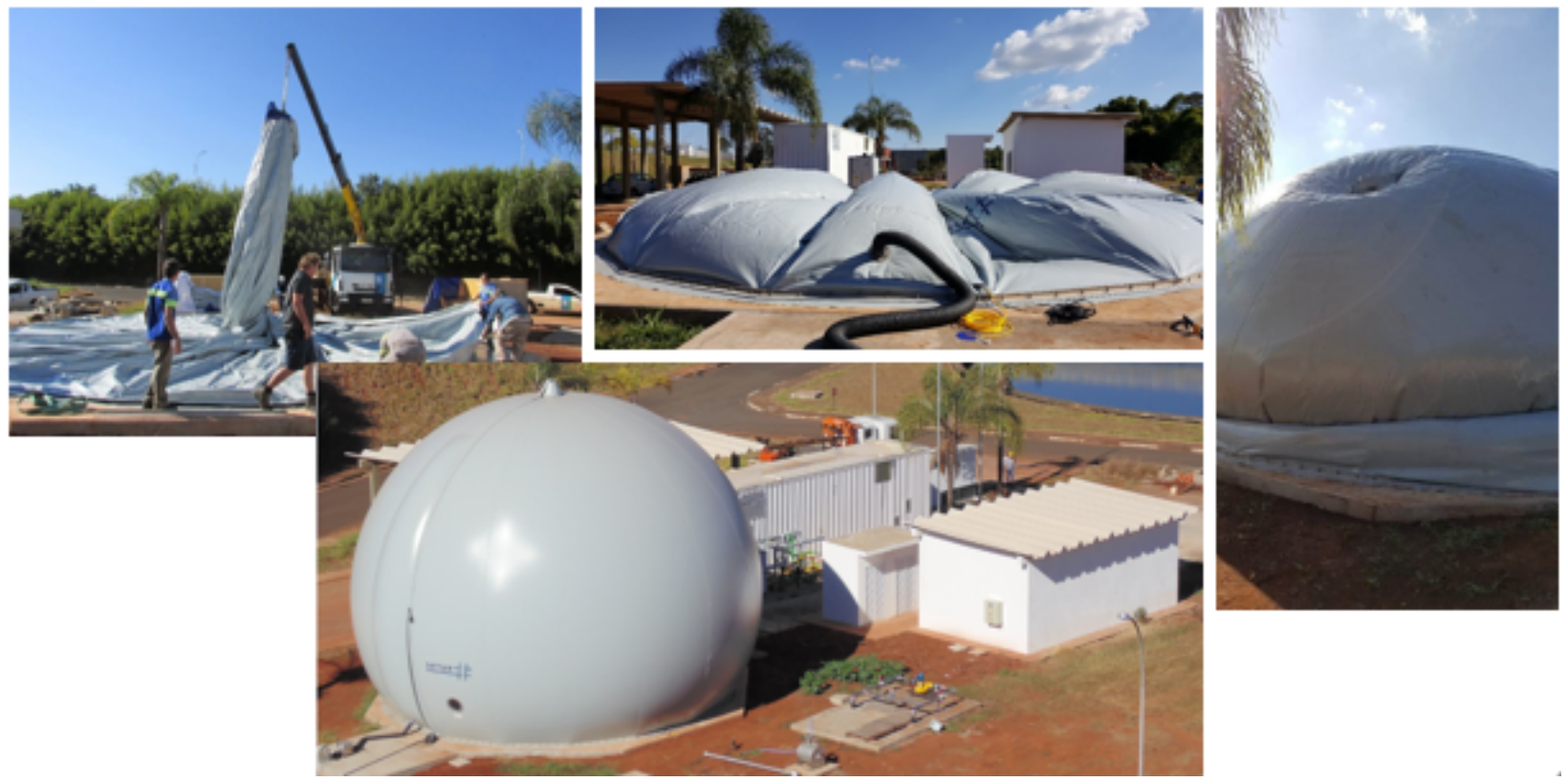

Figura 4 - Sequência de montagem do reservatório de biogás. Fonte: WAELKENS, B.; STERNAD, W., jun/2017 


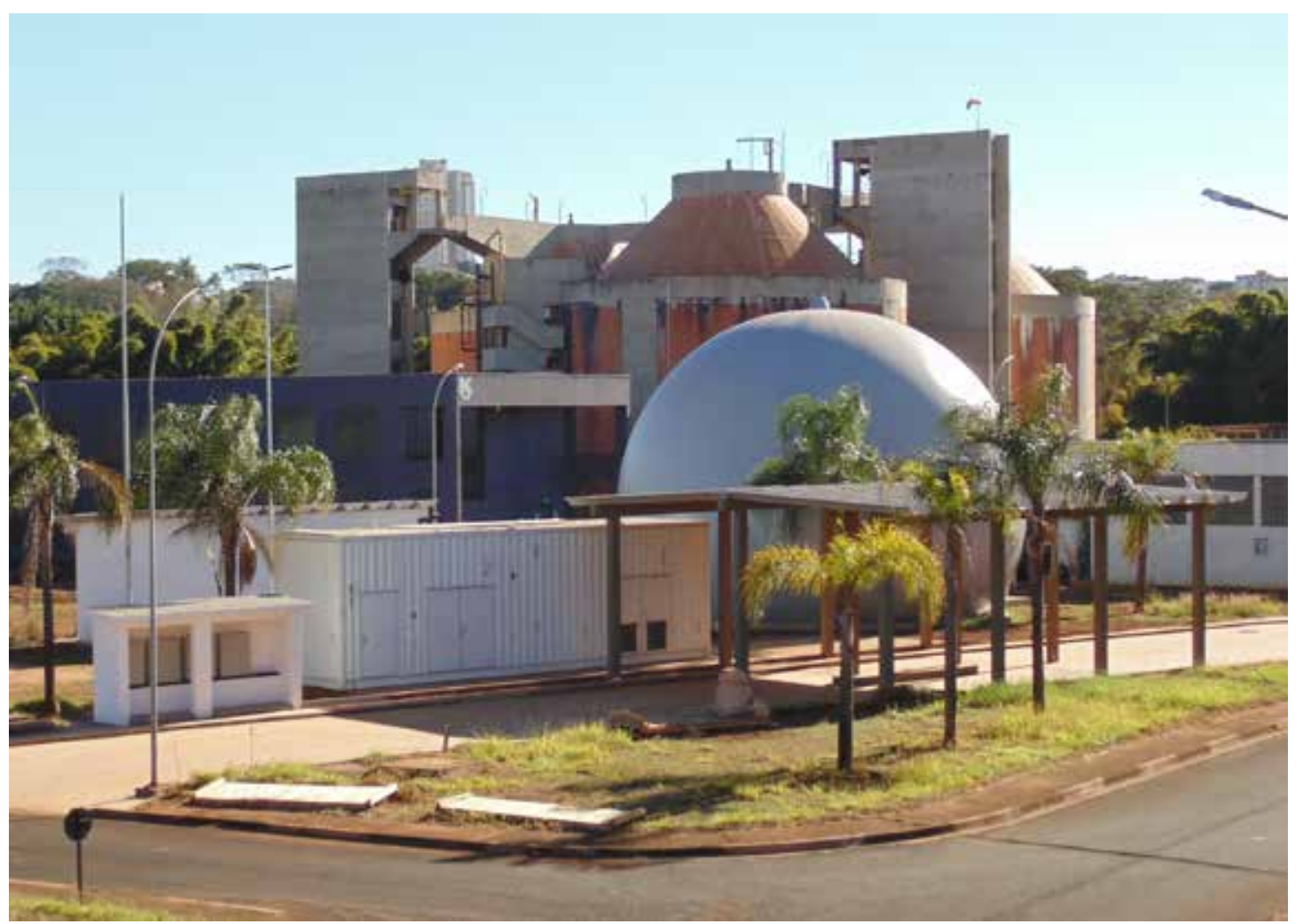

Figura 5- Vista do projeto, com unidade de beneficiamento ao centro, cobertura para instalação do posto de abastecimento à frente, reservatório de biogás à direita, estação de compressão de biometano à esquerda, tendo ao fundo os digestores. Fonte: Sabesp- RG).

Na foto, o "flare" não pode ser visualizado, pois localiza-se atrás de um dos digestores.

\section{CONSIDERAÇÕES FINAIS}

O biogás na forma de biometano é um gás intercambiável com gás natural e também uma fonte de energia renovável despachável, em função das possiblidades de transporte.

Conforme comentado anteriormente, no processo de produção de biometano é utilizada em torno de $80 \%$ da energia contida no biogás para produção de energia limpa e consumidos até $20 \%$ pela tecnologia de tratamento. Esta eficiência de utilização da energia do biogás torna o biometano uma comparação alternativa competitiva a sistemas de cogeração de energia elétrica e calor, onde em geral $33 \%$ a $40 \%$ da energia do biogás é convertida em eletricidade. Se a energia térmica for utilizada, a eficiência global obtida pode variar de 83 a $88 \%$.

Algumas vantagens do uso do biogás de ETEs como fonte de energia para produção de biometano são a produção de forma contínua, a armazenagem e tratamento no local de geração do biogás. O biometano pode, então, ser usado em frota própria ou ser injetado na rede de gás natural nos locais onde essa prática está regulamentada ou em duto dedicado para um cliente específico (por exemplo, uma indústria) ou ser transportado via caminhão. Em todos esses usos, há necessidade de compressão do gás.

Com relação ao projeto de produção de biometano na ETE Franca, foram necessários estudos, pesquisas, busca por normas, por materiais e equipamen- 
tos próprios para biogás, de forma a garantir segurança. Houve muita interação entre os integrantes do projeto para viabilizar: os trâmites administrativos e fiscais para recebimento dos equipamentos doados, os projetos de infraestrutura para instalação dos equipamentos e sua execução, a integração das novas unidades com sistema existente e o comissionamento das unidades.

As próximas etapas incluem: revisão do estudo inicial de viabilidade do projeto de pesquisa, monitoramento da qualidade do biogás e biometano e testes para avaliação dos efeitos de seu uso em veículos. A contabilização dos custos de investimento e dos custos com operação, manutenção, monitoramentos e testes, servirá de referência para planejamento de projetos de uso de biogás.

O projeto representa uma oportunidade de redução de gases de efeito estufa com o uso de biometano em veículos e de inovação tecnológica, com elaboração de projetos de infraestrutura, implantação, operação e monitoramento unidade de beneficiamento de biogás e avaliação de tecnologia para produção de biometano e dos efeitos de sua utilização como combustível veicular, de acordo com as exigências e especificações da ANP.

O comissionamento de todas as instalações contou com a presença do parceiro alemão- Fraunhofer IGB e dos fornecedores dos equipamentos doados e participação da Sabesp.

A partida do sistema está prevista para início de 2018, após conclusão de todos os testes e verificações e atendimento das exigências dos órgãos reguladores. A partir desta fase serão iniciados os monitoramentos para avaliar o desempenho da tecnologia implantada, a qualidade do biometano e o seu efeito nos veículos.

\section{REFERÊNCIAS}

AGÊNCIA NACIONAL DO PETRÓLEO, GÁS NATURAL E BIOCOMBUSTÍVEIS. ANP $\mathbf{n}^{\circ} \mathbf{8 / 2 0 1 5}$ - Resolução para biometano oriundo de produtos e resíduos orgânicos agropastoris e comerciais destinado ao uso veicular e às instalações residenciais, industriais e comerciais a ser comercializado em todo o território nacional.

AGÊNCIA NACIONAL DO PETRÓLEO, GÁS NATURAL E BIOCOMBUSTÍVEIS. ANP $n^{\circ} \mathbf{6 8 5 / 2 0 1 7}$ Estabelece as regras para aprovação do controle de qualidade e a especificação do biometano oriundode aterros sanitários e de estações de tratamento de esgotos destinado ao uso veicular e às instalações residenciais, industriais e comerciais a ser comercializado em todo o território nacional.

AGÊNCIA REGULADORA DE SANEAMENTO E ENERGIA DO ESTADO DE SÃO PAULO. ARSESP Nº 744/2017-Dispõe sobre as condições de distribuição do biometano na rede de gás canalizado no Estado de São Paulo, e dá outras providências.

BEIL, M. Efficient upgrading and biomethane grid injection. In: BIOGAS ZUR GEWWINNUNG VON BIOMETHAN, 2017, Verona.

BILLIG, E.; THRAEN, D. Renewable methane -A technology evaluation by multi-criteria decision making from an European perspective. Energy 2017, 139, 468-484.

BUDZIANOWSKI, W.M.; WYLOCK, C.E.; MARCINIAK, P.A. Power requirements of biogas upgrading by water scrubbing and biomethane compression: Comparative analysis of various plant configurations. Energy Convers. Manag. 2017, 141, 2-19.

CUCCHIELLA, F. et al ,. Biomethane: A Renewable Resource as Vehicle Fuel, October 2017.

DEUTSCHE ENERGIE AGENTUR - DENA. Resources The Role of Natural Gas and Biomethane in the Fuel Mix of the Future in Germany. Disponível em: https://www.Dena.De/en/home/. Acesso em: 21/11/2017. DENA, 2010.

DEUTSCHE ENERGIE AGENTUR - DENA. The Role of Natural Gas and Biomethane in the Fuel Mix of the Future in Germany. Disponível em: https://www.Dena.De/en/home/. Acesso em: 17/11/2017.

EBERT MIKI, R. Projeto de beneficiamento de biogás para uso veicular na ETE Franca da Sabesp: estágio atual e etapas futuras. In: Congresso ABES FENASAN, 2017, São Paulo.

EUROPEAN BIOGAS ASSOCIATION - EBA. BIOGAS AND BIOMETHANE Report 2015. Disponível em: http://european-biogas.Eu/. Acesso em: 21/11/2017.

EUROPEAN COMMISSION - EC. Closing the Loop -An EU Action Plan for the Circular Economy. Disponível em: http://ec.Europa. Eu/environment/circular-economy/index_en.Htm. Acesso em: 21/11/2017.

GROPE, J. Concepts of Biomethane Production from Organic Waste and Residues. https://energie-fr-de.eu/.../conference-sur-le-biogaz-dans-la-chain Acesso em: 21/10/2017.

POLO, C. et al. State of the Art Review of Digester Gas Treatment and Upgrading Technologies. Proceedings of the Water Environ- 
ment Federation, Residuals and Biosolids 2017, pp. 679-699 (21): Water Environment Federation.

PROBIOGÁS. Guia técnico de aproveitamento de biogás em Estações de Tratamento de Esgoto - ETE. Coletânea de publicações do Probiogás, Brasília, 2015. Disponível em: https://www.giz.de/ en/downloads/probiogas-guia-etes.pdf.

MILTNER, M.; MAKARUK, A.; HARASEK, M. Review on available biogas upgrading technologies and innovations towards advanced solutions. J. Clean. Prod. 2017, 161, 1329-1337.

SCHLUTE-SCHULZE B., A. Green Gas/Biomethan in Deutschland: Status Quo 2006 der technischen Möglichkeiten und Kosten der Biogasaufbereitung. In: Green Gas Kongress, Berlim, 2006.
URBAN, W., GIROG, K., LOHMANN, H. Technologien und Kosten der Biogas, 2013.

VAN G.; LEGUIJT, C.; TALLAT-KELPSAITE, J. Supporting mechanisms for the development of biomethane in transport. Delft, CE Delft, Março, 2017. Disponível em: www.cedelft.eu.

WAELKENS, B.; STERNAD, W. Memorial Descritivo do Sistema de Beneficiamento de Biogás, Fraunhofer IGB, 2011.

WILKEN, D. et al. Biogas to Biomethane, UNIDO, Setembro, 2017. Disponível em: www.biogas-to-biomthane.com.

WOJCIECH M. et al.. Power requirements of biogas upgrading by water scrubbing and biomethane compression: comparative analysis of various plant Configurations. Energy Convers. Manag. 2017, 141, 2-19. 